\title{
The development of e-commerce infrastructure in modern conditions
}

\author{
Akhmetova Zaures ${ }^{1}$, Baimukhanbetova Elmira ${ }^{1}$, Belgozhakyzy Moldir ${ }^{1}$, Alikbaeva Ainur ${ }^{2}$ and \\ Tulebaeva Nazym ${ }^{1}$
}

${ }^{1}$ Al-Farabi Kazakh National University, 050040, 71, al-Farabi Ave, Almaty, Kazakhstan

${ }^{2}$ Almaty Management University, 050060, 227, Rozybakiyev str, Almaty, Kazakhstan

\begin{abstract}
The article explores the e-commerce infrastructure. The factors that influence the development of e-commerce are highlighted. The relevance of the role of e-commerce in the world economy is gaining its importance and the use of electronic virtual tools in modern conditions has shown the result of the experience of developed countries which brings efficiency to any country or industry.

It is proved that for the application of effective methods of e-commerce development it begins with the construction of its infrastructure, which contains factors affecting the development of this industry. The study also examines the trend and prospects for the development of electronic commerce in Kazakhstan. The dynamics of foreign countries is shown. The e-commerce development tools are considered, some problems of the development of the e-commerce infrastructure are identified and ways to solve them are proposed.
\end{abstract}

Keywords: e-commerce, infrastructure, trade, market, marketing, information services, Internet marketing, analysis

\section{INTRODUCTION}

New global changes caused by the introduction of innovative and smart technologies have affected the sales market, as well as their participants. A new technological phenomenon of promoting goods and services in meeting the needs of the so-called information-network economy is observed. The information and network economy is the entire global system where there is a relationship between market participants or economic agents via the Internet or other electronic virtual means, which brings efficiency to any country or industry. The information and network economy is a large system that contains several elements, one of which can be called e-commerce.

The study of e-commerce has long gained relevance in foreign countries from both a practical and a scientific point of view. Indeed, in practice, it has shown its attractiveness and effectiveness of its application, in that it requires a lower cost price or may not be required at all, through it you can easily access a large market, it has the ability to differentiate services and provide efficient service for any consumer, despite at his location.

E-commerce can be explained not only as a simple type of trade, its concept is broader and it is based on the use of innovative information technologies. It is also one of the largest systems in marketing, which consists of several business processes.

The technologies used in e-commerce are diverse and they are more based on information-supporting technologies such as:

- email, Internet, intranet (information exchange within the company);

- EDI (Electronic Data Interchange - electronic data interchange);

- extranet (exchange of information with the outside world).

Also, the sphere where e-commerce systems are used is quite specific and each has its own application approach. They are diverse in that each has its own range of business operations (business operations) and transactions. These include operations:

- organization of a meeting of potential customers and suppliers in the market and further contacting;

- providing special databases or electronic exchange of necessary information;

- customer support not only in the pre-sale process, but also to provide high-quality after-sales service in the electronic store;

- the implementation of the act of the sale of goods or services;

- Providing convenient electronic payment for purchases; 
- ensuring quality distribution and delivery to the buyer;

- Creation of a virtual enterprise, which is a group of independent companies that combine their various types of resources to get the opportunity to provide products and services that are not available to independently functioning firms;

- implementation of independent business processes jointly carried out by the manufacturer and its trading partners.

Areas of activity within which electronic commerce can be carried out are no less diverse.

E-commerce requires several series of activities for its full effective functioning, these include:

- Digital marketing;

- capital investment for the creation of electronic stores and insurance; for it);

- operations for commerce (acceptance of the order, delivery of goods and payment

- cooperation of several companies to create innovative products or services;

- efficient distribution of these innovative products;

- business management (taxation, customs operations, licenses or permits, etc.);

- providing delivery, transportation, transportation of goods and methods of supply;

- Accounting;

- resolution and prevention of conflict situations between companies, consumers, as well as all participants in electronic business and the optimal solution to controversial issues.

The above areas of activity are carried out at different levels of doing business, therefore, electronic commerce has different levels of functioning:

- nationally and internationally. At this level, operations in the field of business organization are carried out on the basis of legislation, and not on technical and technological components (since e-commerce is global in nature).

The international level involves for the most part (compared with the domestic) the complex implementation of the e-commerce system, due to the availability and use of different taxation systems, customs duties, the variety of applicable banking transactions in each country, and for individual agreements between some countries require the intervention of an international organization or community.

At the national level, the e-commerce system operates mainly with the representation of the company on the network, advertising, as well as pre-sales and after-sales support.

- To complete a complete commercial operation on the network, local Internet support is required, which includes online ordering of goods, online or offline tracking of the transportation process, billing and payment methods using electronic methods. And for the above operations, government support and interaction with authorized centers are required in order to fulfill customs and tax obligations.

The elements that make up an e-commerce system are significantly different from the traditional sales system and conventional store procedures. In each of them there is a peculiar composition of elements that consist of different contents.

The peculiarity of the e-commerce system from the traditional type of sales can be called its principal business environment in which this trade takes place. The principle of using e-commerce requires the need to develop indirect methods for managing sales processes and resources that were not previously used in a traditional component environment. And it should be noted that these resources may not require any costs.

There are two main factors that contribute to the development of online sales using e-commerce:

- The Internet has a very wide range, cheap, fast and easily accessible to the public;

- The Internet uses electronic data as a medium for delivering messages / data so that information can be sent and received easily and concisely, in the form of both analog and digital electronic data. According to, traditional trade is mainly the actions of companies selling goods and / or services to generate income in the form of money, which, in turn, produces net income from the difference in income minus market prices plus operating costs [6].

Based on research conducted by Forrester (2001-2003), Minahan, and Degan (2001), Eadie et al compiled the following list of external factors that influence the development of e-Commerce:

- standardized procedures and improved test modes;

- research of competitors in the field of e-Commerce and market data.

- State support.

- Optimal management of transaction and payment costs;

- availability and tracking of the supply chain process to ensure consumer confidence

- availability of the supplier database [7] 
T. Zatonanskaya, O. Dlukhopolsky, I. Chirak and N. Kotis (2019) in their studies concluded that the pace of the spread of Internet technologies and broadband Internet access is much higher in underdeveloped countries due to the later start of the distribution process, then as in high-income countries, the peak of the Internet has passed, and the spread of technology has slowed, approaching the "saturation point". Given the results of the simulation, they argue that the spread of Internet technology undoubtedly contributes to the development of e-commerce. The decentralization processes associated with the creation of unified territorial communities in the country only accelerates the spread of broadband Internet access and this process requires the joint efforts of telecom operators and authorities at different levels of government [8].

Based on the above statements, we can list the main components of the infrastructure that contribute to the development of the e-commerce system (Figure 1):

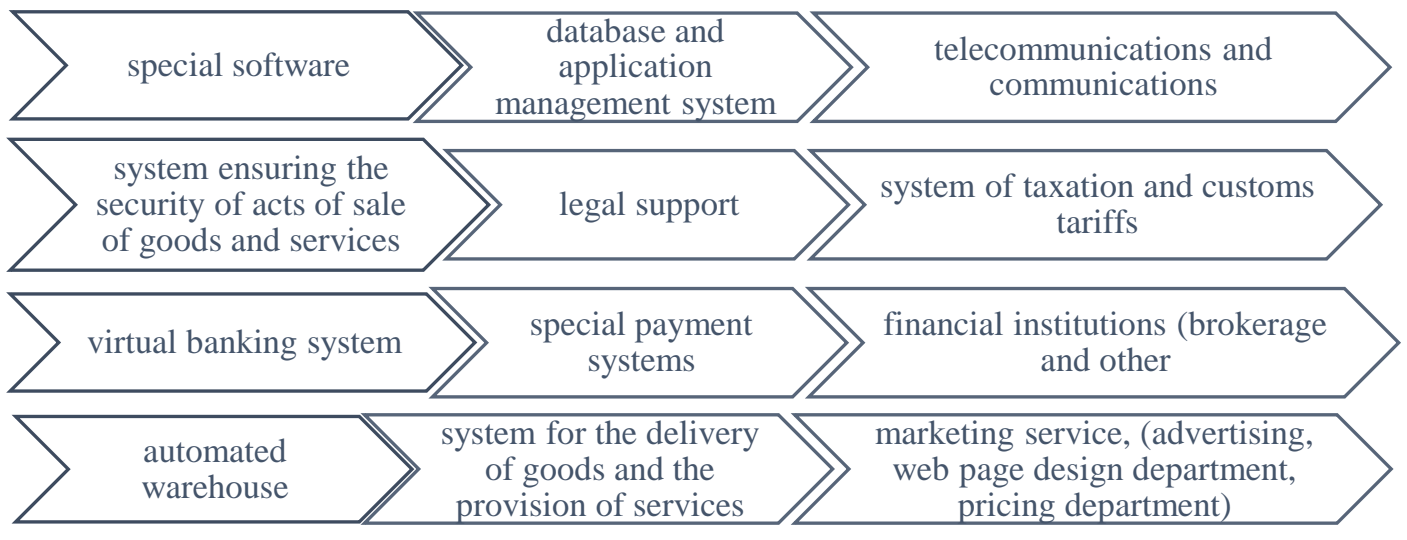

Fig. 1. Elements of e-commerce infrastructure [9]

The components shown in Figure 1 have their own character and a separate approach and capabilities are needed to create each element.

Electronic store. The advantages of this element are that the buyer through the web server, hypertext links and numerous multimedia capabilities, regardless of his location, receive complete reliable information about the product or service of interest to him [10]. If the product converges in terms of the required consumer properties, the buyer can make a decision there and order it regardless of its location. There are various alternatives for implementing an electronic store. Some electronic stores can only accept orders using the Internet transactions and deliveries, such as: selection of goods, direct ordering, and in some you can immediately pay. However, in this case, direct delivery of goods is carried out by the traditional method (goods are cars, computers, household appliances, etc.). In other cases, the use of the Network provides for the possibility of supply through the use of the Internet [11].

In a study by Yongqing Y., Yeming G., Lesley P., Thomas Ch. we have shown the effects of advanced technological capabilities in e-Commerce, using an extended multichannel mode of the e-Commerce platform that allows consumers to make purchases smoothly and efficiently at every stage of e-Commerce development, thus saving the seller's time and costs. In addition, a more reasonable purchase, good price and hightech shopping experience also gives consumers a greater guarantee and they can trust the electronic resource [12].

E-commerce system software. These capabilities include: modules or programming bases (Java, HTML, XML, etc.); templates for embedding and outputting data; multilingual text support; design and methods for making web pages; special software, etc.

HTML (HyperText Markup Language) - a widespread basic set of codes used to create web-documents; if the user's browser is using HTML, he determines in which form to display graphics and other multimedia elements and text.

The software package of the process of managing an electronic store or any part in the field of sales is software that makes it possible to form and maintain a trading system that operates online [13].

The web content management and control service is software that provides the development and support of dynamic information web sites. It also ensures the safety of acts of sale.

An important condition for the effective use of e-commerce is the availability of an inexpensive, secure means of payment [14]. 
Legal support. The organization of electronic commerce and trade should, firstly, be based on the use of traditional legal norms and rules, and secondly, provide for the development of new specialized legal institutions and procedures. In addition, the unification of legislation, as well as the simplification of the rules and procedures used in different countries, is relevant. This implies close cooperation between business and relevant government structures, not only within one country, but also on a global scale $[15]$.

Trends and prospects for the development of e-commerce.

Statista analytic agency compiled and showed a rating of countries in terms of ecommerce efficiency based on four indicators:

- the size of the online market in the country;

- consumer behavior on e-commerce;

- growth potential of e-commerce development;

- e-commerce infrastructure.

Total for 2015-2017 showed that the leader according to the rating are the United States of America, China and Russia, in turn, in terms of the attractiveness of the online market, it occupies a rather high 8 th place.

The global e-commerce market is growing rapidly. In this regard, the relevance of the study of this problem has also increased and many companies are willingly moving into this system. The top 10 countries in terms of e-commerce market size include countries such as China, the USA, Britain, Japan, Germany, France, South Korea, Canada, Russia, Brazil.

Figure 2 shows the analytical rating of the TOP-10 countries:

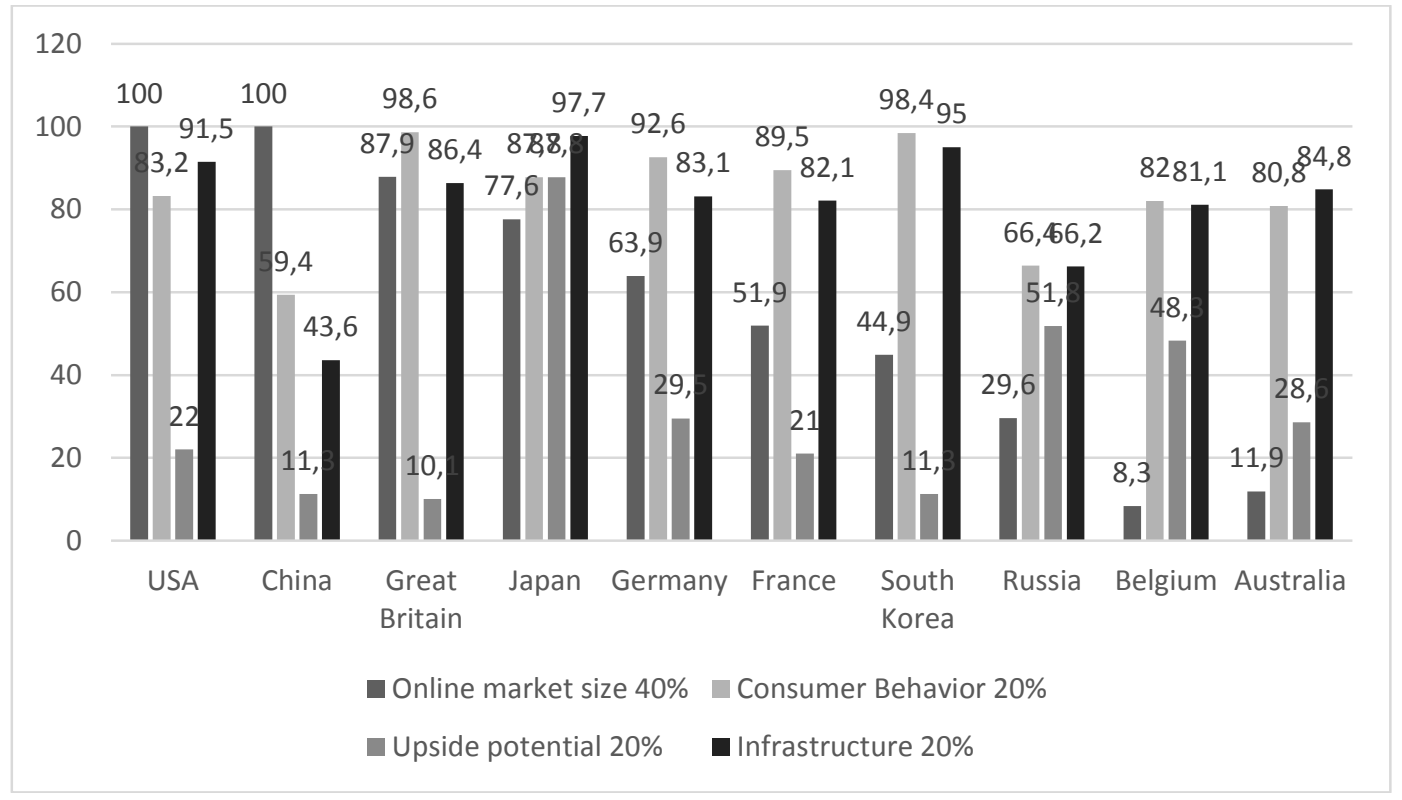

Fig. 2. Ranking of countries by the level of development of electronic commerce

The world ranking, which is shown in Figure 2, is based on 4 indicators.

According to the size of the online market, the leading places are occupied by the countries: USA, China, Great Britain, this growth can be explained by the fact that these have leading online stores like Amazon, Joom, Alibaba, Aliexpress, Taobao and others;

According to the rating of consumer behavior, Great Britain, South Korea and Germany, because in these countries they pay more attention to socio-demographic factors in marketing and often examine the psychological, social position of consumers in the market;

According to the indicator, the growth potential of the e-commerce market in Russia, Germany, Australia, these are countries that are actively developing electronic commerce, apply new technologies and methods to increase the use of electronic commerce. The crisis has had a positive effect on e-commerce for these countries. The need for savings has led to a marked shift in customers from traditional retail to online. Consumers come to e-commerce for a wide range, favorable prices and low-cost delivery;

According to the latter indicator, the infrastructure is developed in Japan, the USA and South Korea, as we said earlier, the main elements of development are related to the 
provision of automation, speed, smart technology and innovative technology to meet consumer needs. As we know, in these countries new technologies are annually produced and in these countries an active stream of innovative ideas.

According to the latter indicator, the infrastructure is developed in Japan, the USA and South Korea, as we said earlier, the main elements of development are related to the provision of automation, speed, smart technology and innovative technology to meet consumer needs. As we know, in these countries new technologies are annually produced and in these countries an active stream of innovative ideas.

This is a picture of only a few countries where e-commerce is actively working and its infrastructure is being created. If we compare this trend with the domestic one, then in Kazakhstan e-commerce is actively growing and the growth potential gains high indicators every year.

The trend in the development of electronic commerce in Kazakhstan is only getting its start, since in 2018 the State program "Digital Kazakhstan" was adopted, which creates the conditions for the transition of the economy of Kazakhstan to a fundamentally new development path that will ensure the creation of a digital economy for the long term. And this factor influenced the development of the introduction of new technologies, especially in the field of sales.

In the Forbes Kazakhstan business magazine, they often write about e-commerce development trends in Kazakhstan. The government pays great attention to the development of this industry and the Digital Kazakhstan Association was created.

On May 24, 2019, the Digital Kazakhstan Association organized a round table and World Bank, Ovum (World Cellular Information Service) data was presented there, which in Kazakhstan $76.4 \%$ of the population were Internet users in 2017. In this ranking, Kazakhstan was in second place after the UK ( $94.8 \%$ of users), even ahead of the United States (76.2\%), Poland (76\%) and Russia (76\%). In terms of the growth rate of card payments, Kazakhstan ranks first in the world - from 2013 to 2017, the average weighted growth was $20.5 \%$ per year. "This is more than $1 \%$ of Kazakhstan's GDP [16].

As for the next element of the e-commerce infrastructure, we can say that the Legislation that regulates e-commerce is at the very beginning of its formation. Kazakhstani legislation is now balanced, and this allows business to develop so far. But improving consumer protection tools for e-commerce remains relevant.

Since e-Commerce in Kazakhstan is at the very initial stage, we can conclude that the e-Commerce infrastructure has not yet been formulated.

As a result of identifying the factors that form the infrastructure of the e-Commerce market, we would like to highlight the factors that hinder its development. These factors are shown in figure 3 :

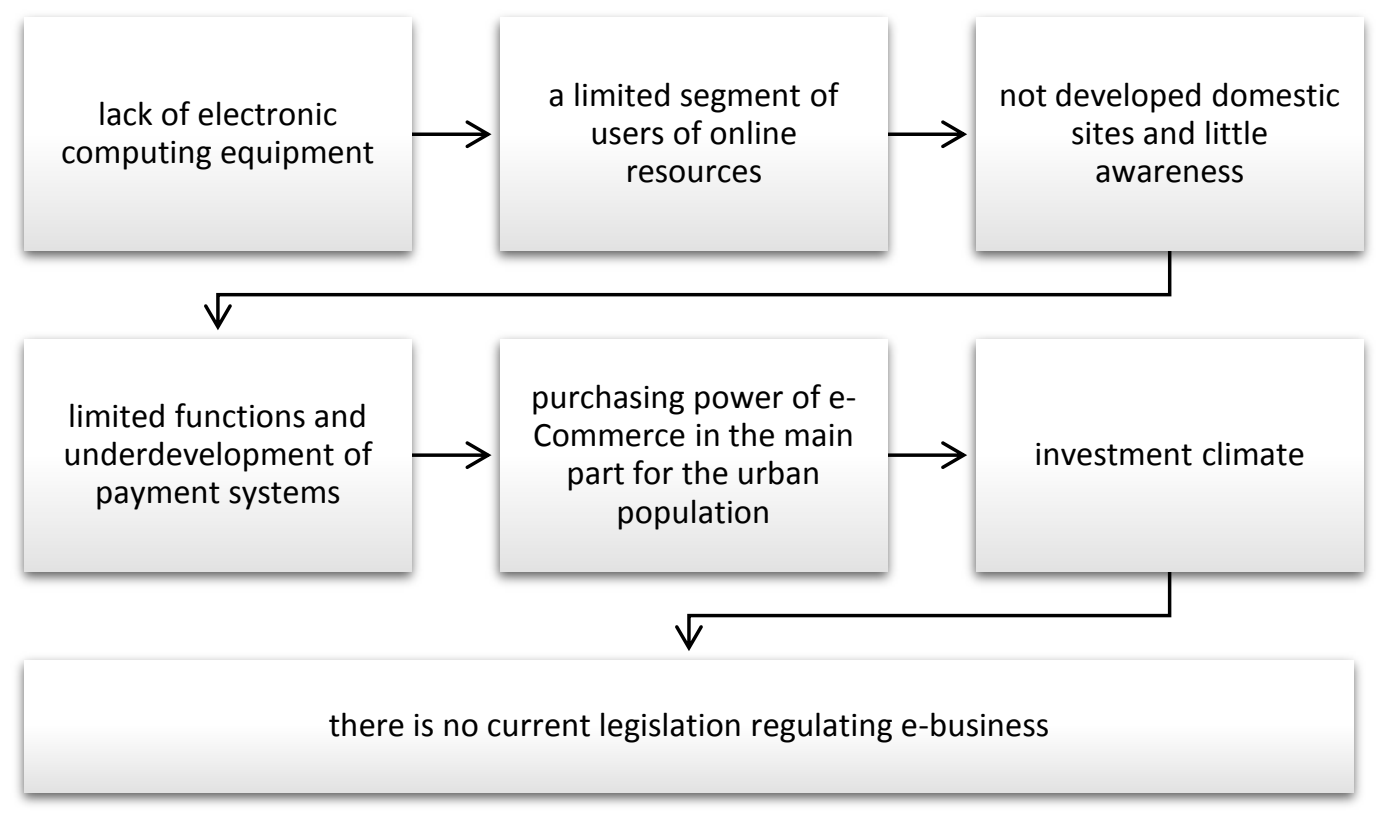

Fig. 3. Factors impeding the development of e Commerce

Identifying factors that shape the e-Commerce infrastructure affects the definition of the main methods of e-Commerce development. It will also be possible to identify the strengths of this industry and develop them gradually in the future. 


\section{Results}

Thus, we believe that the development of an e-commerce infrastructure is a great way to increase brand loyalty in the digital economy, especially since it allows direct exposure and creates a channel without intermediaries with potential customers in a large arena. The need to develop an e-commerce infrastructure requires a completely new format for the sales method and maximum satisfaction of consumer needs. Thus, for such a result, it is necessary to identify a number of factors that create the e-commerce infrastructure:

Attract all companies in the field of sales of goods and services to the creation of a personal web server and accessibility for all consumers;

Creation of special software where there will be all company representatives who sell goods or provide services.

Development of software systems where the consumer will be able to choose, familiarize himself and pre-see the purchased product or service, where he will be able to purchase discounts, special offers or coupons and all payment channels will be present, as well as evaluated after the sale.

Legal protection of the rights of both the consumer and the party that sells or provides the service. At the moment, as we said earlier, Legislation in the field of electronic commerce requires replenishment of points and improvement. For this, legislative drafts of individual industries are proposed, because the whole market will not be able to refer to one Law. Because, each industry has its own specifics and instruments for regulating consumer rights are also peculiar. Therefore, in the field of electronic commerce, clarification of some nuances is required.

References:

1. Rita Rahayu and John Day. Determinant Factors of E-commerce Adoption by SMEs in Developing Country: Evidence from Indonesia. Procedia - Social and Behavioral Sciences 195 ( 2015 )

2. Aladwani, A. M. A quality-facilitated socialization model of social commerce decisions. International Journal of Information Management, 40, (2018).

3. A.A. Polidi; Z.O. Goukasyan; I.A. Maslova; R.V. Fedorenko. Some Aspects of the Quality of Corporate Governance in Digital Economy. International conference on research paradigms transformation in social sciences on March $15,(2019)$

4. Liu, Q.B., Karahanna, E. The dark side of reviews: the swaying effects of online product reviews on attribute preference construction. MIS Q. 41 (2), 427-448. (2017)

5. Zhao, Y. B., Wu, G. Z., Gong, Y. X., Yang, M. Z., \& Ni, H. G. Environmental benefits of electronic commerce over the conventional retail trade? A case study in Shenzhen, China. Science of The Total Environment, 679, 378-386. (2019).

6. Ahmed Altayyar, Dr. John Beaumont-Kerridgea. External Factors Affecting The Adoption of E-procurement in Saudi Arabian's SMEs

7. Yadova N. E. Current State of the Global E-Commerce Market and the Prospects for its Development. In: Bulletin of Moscow Region State University. Series: Economics, no. 2, (2019)

8. Tetiana Zatonatska, Oleksandr Dluhopolskyi, Iryna Chyrak and Nataliya Kotys. The internet and e-commerce diffusion in European countries (modeling at the example of Austria, Poland and Ukraine). Innovative Marketing , 15(1). (2019)

9. Kaluzhskiy M.L. Elektronnaya kommertsiya: marketingovyye seti i infrastruktura rynka [E-commerce: marketing network and market infrastructure]. Moscow: Ekonomika. P. 63, (2014)

10. T.M. Nisar, G. Prabhakar. What factors determine e-satisfaction and consumer spending in e-commerce retailing? Journal of Retailing and Consumer Services 39 (2017)

11. Danlei Zhang a, Pengyu Zhub, Yanmei Ye. The effects of E-commerce on the demand for commercial real estate. Cities 51 (2016).

12. Yongqing Yanga,b, Yeming Gongc, Lesley Pek Wee Landd, Thomas Chesneyb. Understanding the effects of physical experience and information integration on consumer use of online to offline commerce. International Journal of Information Management (2019)

13. David C.W. Phanga, Kanliang Wangb, Qiuhong Wangc, Robert J. Kauffmanc, Maurizio Naldid. How to derive causal insights for digital commerce in China? A research commentary on computational social science methods. Electronic Commerce Research and Applications 35 (2019) 
14. Zoran V., Dragan V, Marina M., Slobodan R., Katarina P. Analyzing of ecommerce user behavior to detect identity theft. Physica A 511 (2018)

15. Gary D. G., Liem V.N., Munib K. Developing e-commerce marketing capabilities and efficiencies for enhanced performance in business-to-business export ventures. Industrial Marketing Management 78 (2019)

16. Official site Ministry of National Economy of the Republic of Kazakhstan Statistics committeeURL: https://stat.gov.kz/ (2020) 